\title{
Análise de Custos Ambientais em Processos Industriais
}

\author{
Paulo Ricardo Santos da Silva \\ paulors@producao.ufrgs.br \\ Fernando Gonçalves Amaral, Dr. \\ Universidade Federal do Rio Grande do Sul - UFRGS \\ Programa de Pós-Graduação em Engenharia de Produção - PPGEP \\ amaral@producao.ufrgs.br
}

\begin{abstract}
Nos últimos anos, tem-se observado a crescente preocupação das indústrias frente aos problemas relacionados com o meio ambiente. Como resultado, há uma adoção cada vez maior de sistemas de gerenciamento ambiental. No entanto, esses sistemas não informam o quanto as empresas gastam na prevenção e na manutenção da qualidade ambiental. Esse artigo apresenta uma revisão dos principais trabalhos publicados na literatura que demonstram como essa avaliação pode ser realizada. Além disso, propõe uma abordagem sistemática que pode contribuir e auxiliar as empresas na quantificação dos custos ambientais associados aos seus processos produtivos.
\end{abstract}

Palavras-chave: gestão ambiental; custos ambientais; modelos de avaliação

In the last years, industries have concerned about environmental problems. As result, they have been adopting environmental management systems. However, they don't inform companies how much is the prevention and environmental quality maintenance costs. This article presents a review about models and methodologies that have been applied in environmental costs evaluations. Moreover, a new approach is considered that will be able to help industries to evaluate their environmental costs.

Keywords: environmental management; environmental costs; evaluation models

\section{Introdução}

Atualmente, mais de 30.000 empresas no mundo estão utilizando sistemas voltados para a gestão ambiental, sendo que este número tende a aumentar rapidamente, devido à busca por um melhor desempenho nessa área (AMMENBERG e HJELM, 2002). Esta crescente preocupação com o meio ambiente motivou o desenvolvimento de técnicas para incorporar aspectos desta origem no projeto e na operação de processos industriais (BAKSHI, 2000). No entanto, conforme Regatschnig e Schnitzer (1998), somente o desenvolvimento de tecnologias para o controle de rejeitos e a integração de aspectos ambientais nos sistemas de gerenciamento não é suficiente para tornar a proteção ao meio ambiente uma prática efetiva nos processos produtivos. Faz-se, então, necessário integrar conhecimentos econômicos aos ecológicos. Para isso, torna-se importante que as empresas possam quantificar e interpretar os custos resultantes da geração de rejeitos.

Neste aspecto, Meinders e Meuffels (2001) afirmam que a maioria das preocupações ambientais pode ser relacionada com aspectos econômicos, uma vez que a redução no consumo de materiais e de energia está diretamente ligada com benefícios financeiros. No entanto, segundo Golonka (1996) apud Burgess e Brennan (2001), não há na literatura uma metodologia consolidada que seja capaz de integrar esses dois assuntos, embora alguns estudos, como o realizado por Azapagic e Clift (1999), tenham procurado alcançar tal objetivo (BOUSTEAD, 1995, apud BURGESS e BRENNAN, 2001). 
Segundo Campos (1996), mensurar custos relacionados ao meio ambiente é uma tarefa difícil, pois eles são compostos por uma grande parcela de intangíveis, isto é, custos de difícil percepção e relacionados indiretamente com aspectos ambientais, como por exemplo a perda de mercado devido à imagem ambiental negativa da empresa. Outro aspecto salientado pelo autor é o fato de muitas empresas tratarem esses custos como externalidades, ou seja, um custo social. Benakouche e Cruz (1994) tornaram esse conceito mais claro, ao citarem o exemplo fictício das conseqüências da instalação de uma fábrica de cimento em uma região agrícola. Eles identificaram que a empresa lançava ar quente com partículas de pó na atmosfera, o qual atingia os campos da região, provocando a perda na qualidade e na quantidade de produção da lavoura, gerando assim perdas para os agricultores. Se essas perdas não forem recompensadas diz-se, então, estar criado um custo externo, ou externalidade. Campos (op. cit.) menciona ainda outro aspecto que dificulta a mensuração de custos ambientais, o fato de que os sistemas de custeio existentes apresentam falhas ao identificar os próprios custos de seus produtos, bem como as perdas do processo produtivo.

Dentro desse contexto, o presente estudo visa realizar uma revisão das principais metodologias de avaliação de custos ambientais encontradas na literatura e propor uma abordagem para auxiliar as empresas a identificar e quantificar os gastos relacionados com a prevenção e manutenção do meio ambiente.

\section{Definições e categorias de custos ambientais}

A disseminação da poluição ambiental foi provocada por dois fatores fundamentais. Primeiro, os recursos naturais eram abundantes e tratados como bens livres, ou seja, para os quais não havia necessidade de trabalho para sua obtenção (DONAIRE, 1999). Outro aspecto relevante é a falta de uma conceituação clara e objetiva dos custos relacionados à degradação ambiental (CAMPOS, 1996).

É nesse contexto que o termo custo ambiental tem sido freqüentemente empregado. No entanto, como salienta Jasch (2003), dependendo dos interesses envolvidos, ele pode incluir uma variedade de custos, tais como a disposição de resíduos, os investimentos na área ambiental e, algumas vezes, os gastos envolvidos na correção de problemas ambientais que ocorrem fora da empresa. Para ilustrar tais considerações, a Figura 1 apresenta algumas definições de custos ambientais segundo a literatura específica relacionada.

\begin{tabular}{|l|l|}
\hline \multicolumn{1}{|c|}{ Autor } & \multicolumn{1}{c|}{ Definição } \\
\hline Hansen e Mowen (2001) & $\begin{array}{l}\text { São custos incorridos porque existe, ou porque pode } \\
\text { existir, uma má qualidade ambiental. }\end{array}$ \\
\hline Eagan e Joeres (2002) & $\begin{array}{l}\text { São os custos pagos pela empresa devido aos impactos } \\
\text { ambientais resultantes da manufatura de seus produtos. }\end{array}$ \\
\hline Jasch (2003) & $\begin{array}{l}\text { Compreende os custos internos e externos que surgem } \\
\text { devido a danos ao meio ambiente ou a sua proteção }\end{array}$ \\
\hline Regatschnig e Schnitzer (1998) & $\begin{array}{l}\text { São custos que podem aparecer como o resultado das } \\
\text { atividades ambientais da empresa, ou seja, atividades } \\
\text { estabelecidas em lei ou voluntárias, que visam evitar, } \\
\text { reduzir, tratar ou dispor os seus rejeitos e emissões , } \\
\text { mas que podem ser resultantes da falta de políticas } \\
\text { ambientais na organização. }\end{array}$ \\
\hline
\end{tabular}

Figura 1 - Definição de custos ambientais de acordo com os principais autores analisados

Como pode-se observar pela Figura 1, as definições de custos ambientais apresentadas possuem graus de abrangência distintos. Cada autor associa a sua definição a outros conceitos, de acordo com a dimensão que deseja dar aos custos ambientais. Por exemplo, quando Eagan e Joeres (2002) referemse aos impactos resultantes da manufatura de produtos, estão excluindo os custos relacionados com a prevenção de problemas ambientais. Por outro lado, Jasch (2003) inclui o termo "proteção" o que dá a conotação de considerar em sua análise os custos de prevenção. Regatsching e Schnitzer (1998) mencionam os termos "atividade ambiental" e "política ambiental", os quais revelam que em sua 
definição de custos ambientais não são consideradas apenas questões operacionais, mas também administrativas.

Como conseqüência da falta de uma definição única e abrangentre para custos ambientais, sua classificação em categorias também apresenta variações de acordo com cada autor. De uma maneira geral, as categorias de custos ambientais encontradas na literatura surgiram da analogia com os custos da qualidade. Conforme Chandrashekar, Dougless e Avery (1999), as técnicas que foram desenvolvidas para reduzir os custos da qualidade podem trazer resultados similares quando aplicadas ao tratamento de problemas ambientais. Inclusive, segundo esses autores, a integração de métodos da Gestão da Qualidade Total (Total Quality Management - TQM) e da Gestão Ambiental promoveram o desenvolvimento da filosofia da Gestão da Qualidade Ambiental Total (Total Quality Environmental Management - TQEM), a qual já está sendo utilizada por muitas organizações. A Figura 2 apresenta um paralelo entre as categorias de custos da qualidade e de custos ambientais.

Genericamente, pode-se dizer que as categorias de custos ambientais são essas apresentadas acima. No entanto, observa-se que, em função do modelo de avaliação de custos proposto por cada autor, os tipos de custos pertencentes a cada categoria e, até mesmo a sua denominação, podem sofrer algumas modificações. Logo, como essa classificação está relacionada com o modelo analisado, a sua discussão será apresentada no próximo item que trata de modelos de avaliação de custos ambientais.

\begin{tabular}{|l|l|l|}
\hline \multicolumn{1}{|c|}{ Categorias } & \multicolumn{1}{|c|}{ Tipos de custos da qualidade } & \multicolumn{1}{c|}{ Tipos de custos ambientais } \\
\hline Prevenção & $\begin{array}{l}\text { Custos de treinamento de operadores, } \\
\text { custos para reprojetar um produto }\end{array}$ & $\begin{array}{l}\text { Custos de reprojeto de } \\
\text { processos e produtos e custos } \\
\text { com treinamento de } \\
\text { empregados }\end{array}$ \\
\hline Avaliação & $\begin{array}{l}\text { Custos de testes e calibração de } \\
\text { equipamentos }\end{array}$ & $\begin{array}{l}\text { Custos de monitoramento de } \\
\text { equipamentos e com pessoas } \\
\text { para checar a qualidade } \\
\text { ambiental }\end{array}$ \\
\hline Falhas internas & $\begin{array}{l}\text { Custo de retrabalho e segregação de } \\
\text { produtos }\end{array}$ & $\begin{array}{l}\text { Custo de disposição em aterros } \\
\text { e de separação de rejeitos }\end{array}$ \\
\hline Falhas externas & $\begin{array}{l}\text { Custos de garantia e custos de } \\
\text { responsabilidade }\end{array}$ & $\begin{array}{l}\text { Custos de obrigação social e de } \\
\text { limpeza e despoluição de rios e } \\
\text { lagos }\end{array}$ \\
\hline
\end{tabular}

Figura 2 - Paralelo entre as categorias de custos da qualidade e categorias de custos ambientais. Fonte: adaptado de Chandrashekar, Dougless e Avery (1999)

\section{Modelos e metodologias para avaliação de custos ambientais}

Conforme Regatschnig e Schnitzer (1998), torna-se cada vez mais importante para as empresas quantificar e interpretar os custos que resultam da geração de emissões e rejeitos, bem como o benefício resultante da adoção de medidas preventivas, como esquematicamente apresentado na Figura 3. Para isso, as empresas necessitam de respostas claras e objetivas para as seguintes questões:

- Quais são as atividades realizadas na empresa que possuem conseqüências ambientais?

- Qual é o custo dessas atividades?

- Quais são as vantagens que a empresa obtém com estas atividades?

- Onde podem ser reduzidos os custos? 


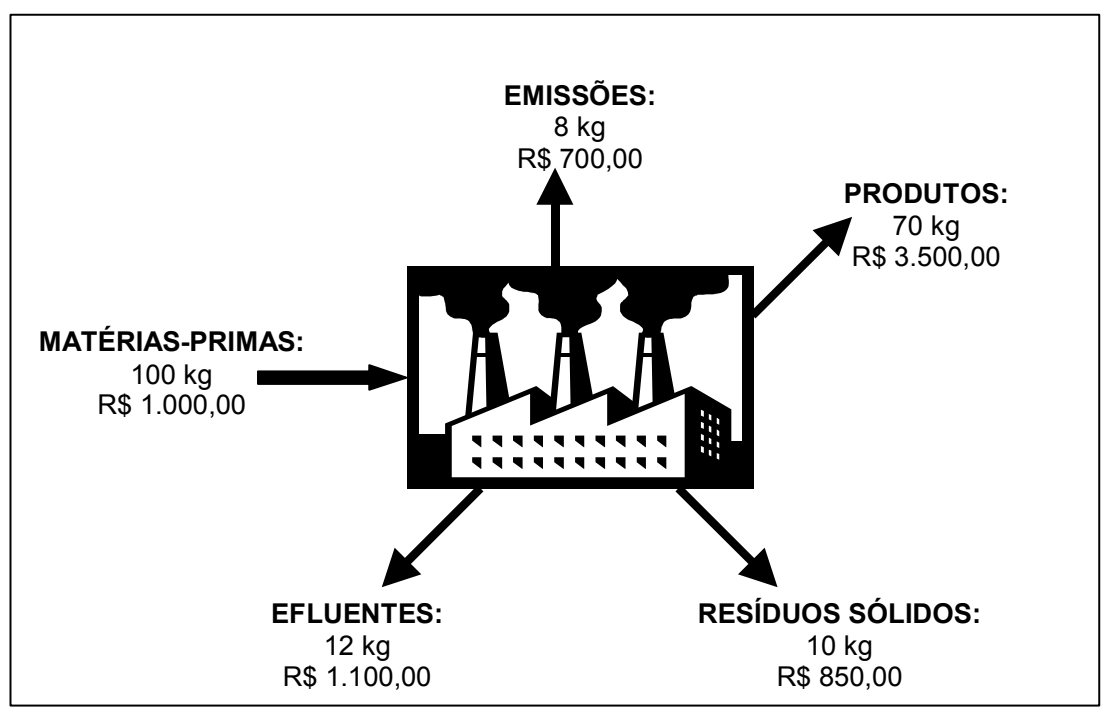

Figura 3 - Relação entre impactos e custos ambientais na indústria (adaptado de REGATSCHNIG e SCHNITZER, 1998)

Regatschnig e Schnitzer (1998) complementam ainda que não há definições padronizadas, nem um sistema de custeio apropriado, quando se trata de custos ambientais. Desta forma, as análises realizadas dependem do interesse de quem as está conduzindo. Por exemplo, podem ser focadas apenas nos custos de disposição de rejeitos ou nos custos de investimentos em projetos de recuperação ambiental. Assim, torna-se difícil realizar comparações entre os custos ambientais das empresas.

Para suprir essas necessidades, alguns autores têm apresentado modelos e metodologias de avaliação de custos ambientais, muitos dos quais estão baseados na metodologia de avaliação de custos da qualidade.

\subsection{Modelo para custos ambientais (Model For Environmental Costs - MEC)}

Trata-se de um dos primeiros modelos encontrados na literatura desenvolvido para avaliar custos ambientais. Foi proposto por Diependaal e Walle (1994). Adota as seguintes categorias de custos:

a) Custos de prevenção - nessa classe estão envolvidos todos os custos necessários para evitar a degradação ambiental. Como exemplo, pode-se citar os gastos com a implementação ou mudanças na política ambiental da organização, a pesquisa e o desenvolvimento de novas matérias-primas com melhor desempenho ambiental e a implantação de procedimentos ambientais preventivos.

b) Custos de correções integradas ao processo - aqui são considerados os custos envolvidos na modificação do processo produtivo, a fim de reduzir a geração de emissões e de rejeitos. Nesta categoria, estão incluídos os custos de instalação e de manutenção de sistemas de integração de processos e a reutilização de rejeitos dentro do processo produtivo.

c) Custos de correções dos efeitos do processo - são os custos devido ao tratamento de fim de tubo (end of pipe), incluindo os gastos com o monitoramento de emissões existentes. Os custos de instalação de uma estação de tratamento de efluentes, de controle e operação dos equipamentos desta estação e de equipamentos de medição e controle de emissões são incluídos nessa classe.

d) Custos devido a falhas internas - são os custos associados à limpeza ou à disposição final de poluentes na área interna da empresa. Como exemplo, pode-se citar os custos com a recuperação de solos contaminados dentro da área da empresa e os custos de transporte e disposição de resíduos.

e) Custos devido a falhas externas - inclui os custos relativos à limpeza e à disposição final de poluentes fora dos limites da empresa. Nesta categoria, estão incluídos os gastos com a recuperação de solos contaminados fora da área da empresa devido à disposição imprópria 
de rejeitos e o pagamento de taxas relativas à produção de emissões ou de efluentes fora das especificações previstas na licença de operação da empresa.

Segundo os autores desse modelo, os custos associados a cada uma das categorias anteriores são um indicativo da preocupação da empresa em relação à questão ambiental, conforme pode ser observado na Figura 4. Em geral, custos de falha elevados refletem a deficiência ambiental da empresa. Por outro lado, os altos custos de prevenção e de correção integrados ao processo indicam a forte preocupação com o meio ambiente. Portanto, esse modelo permite gerenciar essas parcelas de custos e fornece a quem toma decisões uma ferramenta capaz de definir o quanto deve ser investido em cada uma das categorias supra citadas. Tal modelo foi empregado em uma indústria moveleira, concluindo-se que $35,2 \%$ dos custos ambientais totais eram empregados para correção de efeitos produzidos pelo processo ao meio ambiente, enquanto os custos de prevenção correspondiam a apenas $20,5 \%$ do montante total (DIEPENDAAL e WALLE, 1994).

\subsection{Modelo dos Custos da Qualidade Ambiental - CQA}

Campos (1996) desenvolveu esta abordagem para identificar os custos ambientais, através da qual classifica uma série de gastos existentes nas empresas nas seguintes categorias:

a) Custos de adequação - refere-se aos custos necessários para adequar a empresa às tecnologias limpas, às alterações nos processos produtivos, às leis impostas por órgãos competentes e a normas ambientais como a ISO 14.000. Esta categoria se subdivide em custos de prevenção, de correção e de controle. Na primeira classe, são incluídos os custos de contratação de mãode-obra especializada na área ambiental, contratação de consultorias e auditorias ambientais, substituição de matérias-primas, insumos e componentes poluentes, investimentos em pesquisa e desenvolvimento visando produtos e processos menos poluidores, entre outros. Já entre os custos de correção pode-se citar a limpeza de rios, mares e lagos, limpezas de terrenos, tratamento de gases tóxicos e gastos com materiais para a recuperação de danos ambientais. Por fim, os custos de estações de tratamento de efluentes, instalação de filtros, testes e inspeções para verificação dos parâmetros poluentes nos produtos acabados e verificação de métodos e processos fazem parte dos custos de controle.

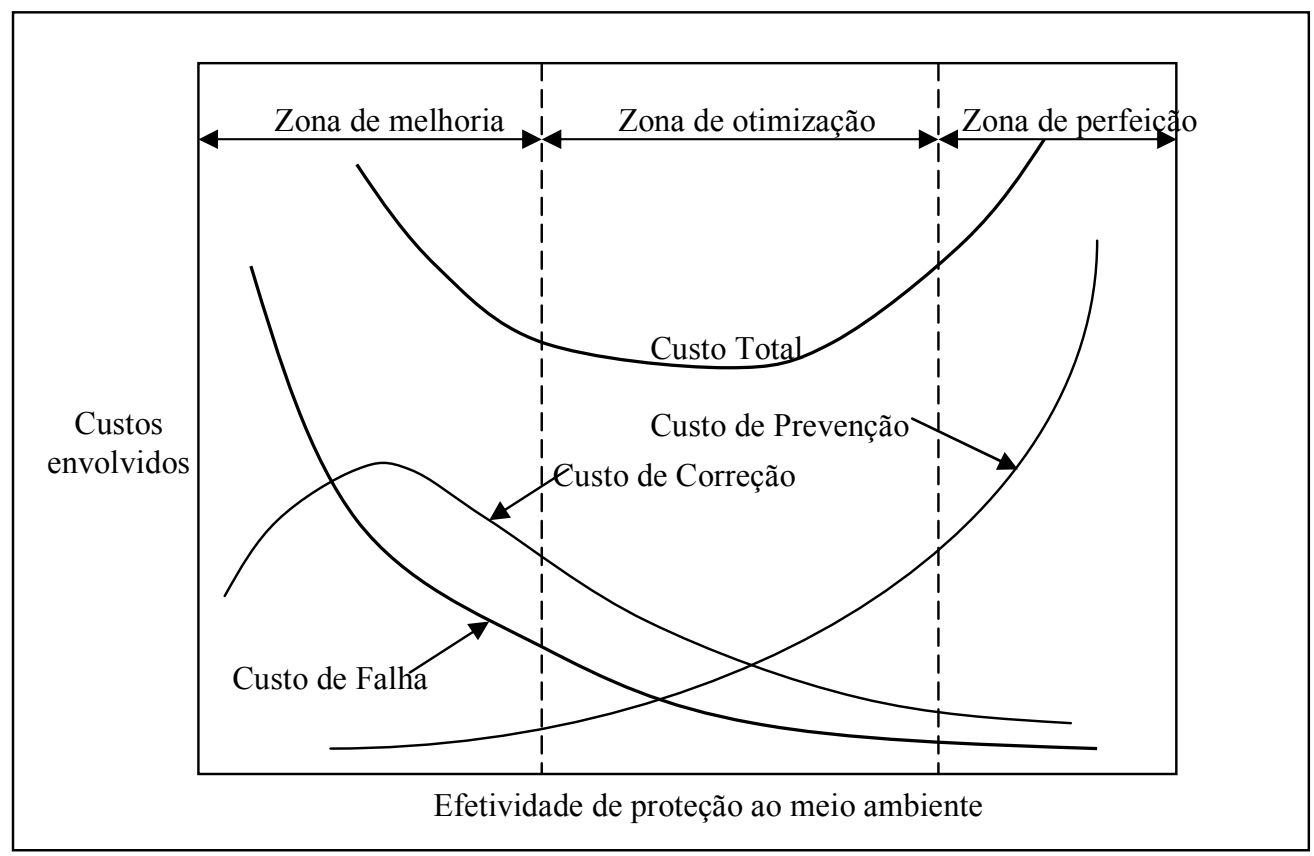

Figura 4 - Relação entre custos de prevenção, de correção e de falhas e a efetividade de proteção ambiental (adaptado de DIEPENDAAL e WALLE, 1994) 
b) Custos das falhas de adequação - nesta categoria estão incluídos os custos empresariais gerados nas falhas do processo de adequação. A ocorrência de tais custos reflete ineficiências dos processos produtivos, bem como desperdícios e retrabalhos. Pode-se citar: o pagamento de multas, indenizações por prejuízos causados, fechamento da empresa, perda de crédito e de permissão de atuação, além da devolução de produtos, como exemplos de custos de falhas de adequação.

c) Custos tratados como externalidades - nesta categoria estão incluídos os custos que não se enquadram corretamente nas anteriores por serem bastante polêmicos, tais como o uso indevido de recursos (água, solo e ar), poluição atmosférica e danos causados à saúde de moradores próximos de indústrias poluidoras.

O modelo desenvolvido por Campos (1996) foi aplicado a uma empresa do setor têxtil, especificamente no setor de tratamento dos efluentes da etapa de estamparia do produtos. O autor analisou cada atividade desenvolvida no processo de estamparia, identificou as possibilidades de falhas, verificando como isso afetaria o processo de tratamento de efluentes e assim listando os possíveis custos envolvidos de acordo com as categorias adotadas.

Como conclusão, Campos (1996) afirma que a falta de uma estrutura baseada em processos dificulta a análise e a quantificação dos custos das categorias adotadas. Por conseqüência, ele propôs que o estudo seria mais efetivo se houvesse um detalhamento das atividades desenvolvidas na empresa, seguido da escolha das atividades mais importantes para serem trabalhadas, com diminuição de seus custos e dos custos da qualidade ambiental.

\subsection{Metodologia desenvolvida por Regatschnig e Schnitzer}

Regatschnig e Schnitzer (1998) desenvolveram uma metodologia para tratar custos ambientais, baseada em atividades, capaz de apurá-los, alocá-los e avaliá-los. A sistemática de análise é composta pelas seguintes etapas:

a) Definir o que será considerado como custo ambiental na análise;

b) Organizar uma equipe multidisciplinar para realizar o estudo. É fundamental que chefes de setores relacionados com áreas de produção e de contabilidade façam parte desse grupo;

c) Classificar os custos nas seguintes categorias: tratamento e disposição de rejeitos, mão-deobra, serviços externos, licenças ambientais, depreciação de equipamentos, manutenção de equipamentos, financiamento de investimentos ambientais e cálculos de riscos;

d) Identificar as atividades, os custos e os lucros ambientais associados às áreas de rejeitos, de energia, de ar ou ruído e de água. O objetivo desta etapa é medir o desempenho ambiental nessas áreas e identificar quais têm maior potencial de melhorias. Dessa forma, o grupo poderá promover estudos mais direcionados. A priorização é estabelecida de acordo com o total investido em cada categoria de custo.

e) Compilar os custos e os lucros ambientais por atividades e por áreas de análise, a fim de identificar oportunidades de melhorias que serão priorizadas em uma análise mais detalhada. Assim, pode-se gerar um sumário com os custos ambientais da organização estudada, como apresentado na tabela 1.

f) Integrar os custos e lucros ambientais no sistema contábil da organização. Somente aqueles que se mostraram relevantes na análise anterior deverão fazer parte do sistema de alocação regular dos custos da empresa 
Tabela 1 - Exemplo de uma matriz de custos e lucros ambientais da metodologia de Regatschnig e Schnitzer

\begin{tabular}{|c|c|c|c|c|c|c|c|}
\hline & \multicolumn{5}{|c|}{ Áreas de análise } & \multirow[b]{2}{*}{ Total } & \multirow[b]{2}{*}{ Priorização } \\
\hline Categorias de Custos & Rejeitos & Energia & Ar/ruído & Água & Outros & & \\
\hline Custos de tratamento e disposição & & & & & & & \\
\hline Custos com mão-de-obra & & & & & & & \\
\hline Custos de serviços externos & & & & & & & \\
\hline Licenças ambientais & & & & & & & \\
\hline Custos dos rejeitos & & & & & & & \\
\hline $\begin{array}{l}\text { Depreciação dos investimentos } \\
\text { ambientais }\end{array}$ & & & & & & & \\
\hline Manutenção & & & & & & & \\
\hline $\begin{array}{l}\text { Financiamento em investimentos } \\
\text { ambientais }\end{array}$ & & & & & & & \\
\hline Avaliação de riscos & & & & & & & \\
\hline Custos totais & & & & & & & \\
\hline Lucros totais & & & & & & & \\
\hline
\end{tabular}

Fonte: Regatschnig e Schnitzer (1998)

Os autores acrescentam ainda uma outra etapa na metodologia que envolve o estabelecimento de relações entre as categorias de custos e as ações que permitam diminuir os seus custos. Isto envolve a troca de materiais utilizados nos processos, as modificações no processo propriamente dito, a adoção de novas tecnologias, as formas de realizar uma recuperação energética e a reciclagem interna de materiais. Dessa forma, em cada categoria é verificada a relação de importância entre a ação proposta e a potencialidade de melhoria, acarretando em redução de custos.

Regatschnig e Schnitzer (1998) concluíram que a condição fundamental para o sucesso da implementação de programas de diminuição da geração de rejeitos é tanto o conhecimento preciso dos custos associados a esses resíduos como a alocação correta desses custos a atividades específicas.

\subsection{Metodologia para a Contabilidade de Gerenciamento Ambiental (Environmental Management Accounting - EMA)}

Essa metodologia foi desenvolvida por Jasch (2003), visando combinar informações de contabilidade finaceira e de custos, bem como do balanço de massa, para aumentar a eficiência material, reduzir impactos e riscos ambientais e diminuir adequadamente os custos da proteção ambiental. A metodologia desenvolvida exclui os custos externos à empresa, focando-se na compreensão dos custos envolvidos no tratamento de rejeitos, proteção e gestão ambiental, assim como na análise de perdas de materiais e de energias devido a ineficiências nos processos produtivos.

Conforme o autor, os custos ambientais incluem outras parcelas além dos gastos com meios de prevenir e tratar rejeitos e emissões. Neste sentido, afirma que o termo rejeito [grifo pessoal] tem um outro significado além do tradicional; para ele os rejeitos são todos os materiais que a empresa compra e não transforma em um produto comercializável. Assim, a geração de rejeitos é um indicativo da ineficiência no processo produtivo. A partir dessas considerações, as categorias de custos ambientais consideradas compreendem: 
a) Custos de disposição de rejeitos e tratamento de emissões - inclui os custos de depreciação de equipamentos e de mão-de-obra relacionados com o tratamento de rejeitos, impostos pagos para dispor resíduos, dívidas pela segurança ambiental, custos para as ações de correção de falhas.

b) Custos de prevenção e gestão ambiental - envolve os gastos com consultorias e mão-de-obra para apoiar as atividades do sistema de gestão ambiental, custos de pesquisa e desenvolvimento, aquisição de tecnologias limpas, incluindo ainda os demais custos de gerenciamento ambiental.

c) Custos de perdas de materiais - compreende os custos de matérias-primas, dos materiais auxiliares, de energia e de água que estão associados com a geração de rejeitos. As relações entre estes e os custos dos rejeitos são obtidas a partir de balanços de massa.

d) Custos de produção de não-produtos - envolve os custos de processamento de materiais relacionados com a geração de rejeitos, tais como mão-de-obra e depreciação de equipamentos. Segundo Jasch (2003), esta parcela dos custos ambientais pode ser mensurada a partir do emprego do Custeio Baseado em Atividades (Activity Based Costing - ABC) ou da Contabilidade do Fluxo de Custos (Flow Cost Accounting).

Na metodologia proposta, o autor ainda avalia as receitas provenientes da venda de rejeitos. Por fim, de maneira análoga ao que é proposto no modelo de Regatschnig e Schnitzer, os custos das categorias de custos ambientais são relacionados com ações sobre o meio ambiente, como pode ser verificado na tabela 2.

A aplicação da metodologia em uma indústria de papel e celulose localizada na Suécia revelou que $44 \%$ de todos os custos ambientais estão relacionados com consumo de água e a geração de efluentes. Além disso, $13 \%$ dos custos anuais de operação estão relacionados ao tratamento de rejeitos , mas os gastos de materiais que são perdidos junto com os efluentes chega a $32 \%$ dos custos. A partir disto, conclui-se que pesquisas para reaproveitamento de materiais é muito importante para a redução dos custos ambientais. Ainda, o estudo concluiu que $80,4 \%$ dos custos ambientais estão relacionados com a perda de materiais, correspondente a perda de matérias-primas, materiais auxiliares e de operação.

\subsection{Modelo de Análise dos Custos Ambientais do Ciclo de Vida (Life Cycle Environmental Cost Analysis - LCECA)}

O modelo LCECA foi desenvolvido por Durairaj et al. (2002), tendo como objetivo a inclusão dos custos ambientais nos custos dos produtos. Neste modelo, adotam-se as seguintes categorias de custos ambientais:

a) Custos de controle de efluentes

b) Custos de tratamento de efluentes

c) Custos de disposição de efluentes

d) Custos de implementação de sistema de gestão ambiental

e) Custos de taxas ambientais

f) Custos de energia

Pela própria proposição dos autores, depreende-se que este modelo é mais adequada para avaliar os custos ambientais de produtos, não de processos industriais. Inicialmente, deve-se selecionar o produto que será analisado, desmembrá-lo e, após, preparar uma lista dos custos para cada parte do produto. $\mathrm{O}$ objetivo do LCECA é definir relações entre o custo total do produto e as categorias citadas acima ao longo de todo o ciclo de vida do produto. 
Tabela 2 - Exemplo de uma matriz de custos e lucros ambientais da metodologia EMA

\begin{tabular}{|c|c|c|c|c|c|c|c|c|c|}
\hline & \multicolumn{8}{|c|}{ Ações sobre o meio ambiente } & \multirow[b]{2}{*}{ Total } \\
\hline $\begin{array}{c}\text { Categorias de custos } \\
\text { ambientais }\end{array}$ & $\begin{array}{l}\text { Ar e } \\
\text { clima }\end{array}$ & $\begin{array}{l}\text { Rejeitos } \\
\text { líquidos }\end{array}$ & $\begin{array}{l}\text { Rejeitos } \\
\text { sólidos }\end{array}$ & $\begin{array}{l}\text { Solo e águas } \\
\text { subterrâneas }\end{array}$ & $\begin{array}{l}\text { Ruido e } \\
\text { vibração }\end{array}$ & $\begin{array}{l}\text { Biodiver } \\
\text { sidade }\end{array}$ & Radiação & Outros & \\
\hline $\begin{array}{l}\text { a) Custos de disposição } \\
\text { e tratamento de rejeitos }\end{array}$ & & & & & & & & & \\
\hline $\begin{array}{l}\text { Depreciação de } \\
\text { equipamentos }\end{array}$ & & & & & & & & & \\
\hline Manutenção & & & & & & & & & \\
\hline $\begin{array}{l}\text { Mão-de-obra } \\
\text { relacionada }\end{array}$ & & & & & & & & & \\
\hline Impostos e taxas & & & & & & & & & \\
\hline $\begin{array}{l}\text { b) Custos de prevenção } \\
\text { e gestão ambiental }\end{array}$ & & & & & & & & & \\
\hline $\begin{array}{l}\text { Consultorias } \\
\text { ambientais }\end{array}$ & & & & & & & & & \\
\hline $\begin{array}{l}\text { Mão-de-obra } \\
\text { relacionada à gestão } \\
\text { ambiental }\end{array}$ & & & & & & & & & \\
\hline $\begin{array}{l}\text { Pesquisa e } \\
\text { desenvolvimento }\end{array}$ & & & & & & & & & \\
\hline $\begin{array}{l}\text { c) Custos de perdas de } \\
\text { materiais }\end{array}$ & & & & & & & & & \\
\hline Matérias-primas & & & & & & & & & \\
\hline Empacotamento & & & & & & & & & \\
\hline Materiais auxiliares & & & & & & & & & \\
\hline Materiais de operação & & & & & & & & & \\
\hline Energia & & & & & & & & & \\
\hline Água & & & & & & & & & \\
\hline $\begin{array}{l}\text { d) Custos de produção } \\
\text { de não-produtos }\end{array}$ & & & & & & & & & \\
\hline $\begin{array}{r}\text { Total de custos } \\
\text { ambientais }\end{array}$ & & & & & & & & & \\
\hline Lucros ambientais & & & & & & & & & \\
\hline $\begin{array}{l}\text { Subsídios e prêmios } \\
\text { ambientais }\end{array}$ & & & & & & & & & \\
\hline $\begin{array}{l}\text { Outros lucros } \\
\text { ambientais }\end{array}$ & & & & & & & & & \\
\hline $\begin{array}{r}\text { Total de lucros } \\
\text { ambientais }\end{array}$ & & & & & & & & & \\
\hline $\begin{array}{r}\text { Razão Custos - Lucros } \\
\text { ambientais }\end{array}$ & & & & & & & & & \\
\hline
\end{tabular}

Fonte: adaptado de Jasch (2003)

\subsection{Modelo Econômico de Controle e Avaliação de Impactos Ambientais - MECAIA.}

Kraemer (2002) desenvolveu este modelo para tratar os custos ambientais dentro de uma abordagem mais abrangente, a inserção da questão ambiental dentro das decisões estratégicas da empresa. Para isso, o autor empregou o método ABC (Activity Based Costing) em conjunto com o BSC (Balanced Scorecard). O modelo proposto está estruturado nas seguintes etapas:

a) Diagnóstico estratégico preliminar - tem como objetivo fazer um reconhecimento geral da empresa e verificar se algumas premissas básicas para a implantação do modelo são satisfeitas.

b) Mapeamento dos processos e atividades empresariais - visando identificar e formalizar a cadeia produtiva da organização analisada, através do detalhamento da organização em nível de processos e atividades. 
c) Identificação dos aspectos e impactos ambientais associados a cada atividade mapeada anteriormente.

d) Determinação dos custos dos processos e atividades, dando-se ênfase aos relacionados com o meio ambiente. Ao final dessa etapa, faz-se a classificação dos processos e atividades em categorias quanto a sua tangibilidade (atividades tangíveis ou intangíveis); ao retorno ambiental proporcionado a empresa (direto ou indireto); e a sua função principal (ações de controle, prevenção ou recuperação). Com essa classificação a empresa poderá se localizar frente à estratégia organizacional e à sustentabilidade almejada.

e) Estruturação das perspectivas ambientais para a elaboração do BSC Ambiental - visando elaborar um mapa estratégico voltado à minimização dos danos ambientais ocorridos em função das atividades empresariais.

f) Análise estratégica ambiental de custo-benefício e propostas de ações de melhoria - têm como objetivo a determinação das relações de custo-benefício quando da minimização dos impactos ambientais que influenciam nos objetivos estratégicos da organização.

A aplicação do modelo de Kraemer foi feita em uma empresa de beneficiamento de couro, a qual é responsável pela geração de um elevado volume de efluentes e resíduos sólidos (aparas, raspas, serragem e pó de couro). Entre as conclusões obtidas, o autor observou a necessidade de um conhecimento profundo das atividades desempenhadas na organização para que as ações ambientais fossem efetivas. Assim, os recursos financeiros consumidos por atividades de recuperação ambiental poderiam ser deslocados para atividades de correção e prevenção.

\section{Comparação entre os modelos apresentados}

Como pode-se observar, cada modelo apresenta vantagens e desvantagens. Para melhor entendê-los, foram estipulados alguns critérios de comparação como pode ser observado no quadro 3. Adota-se a notação $(\sqrt{ })$ para indicar que o modelo contempla o critério analisado.

\begin{tabular}{|c|c|c|c|c|c|c|}
\hline \multirow[b]{2}{*}{ Critérios de comparação } & \multicolumn{6}{|c|}{ Modelos } \\
\hline & 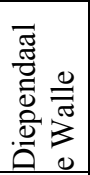 & 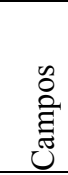 & 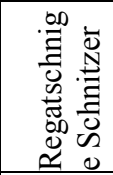 & 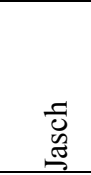 & 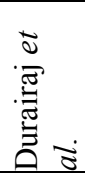 & 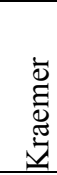 \\
\hline Baseia-se nas categorias de custos da qualidade & $\sqrt{ }$ & $\sqrt{ }$ & & & & $\sqrt{ }$ \\
\hline Quantifica os custos ambientais & $\sqrt{ }$ & & $\sqrt{ }$ & $\sqrt{ }$ & $\sqrt{ }$ & $\sqrt{ }$ \\
\hline $\begin{array}{l}\text { Compara os custos de prevenção e de correção, permitindo o seu } \\
\text { gerenciamento }\end{array}$ & $\sqrt{ }$ & & & & & $\sqrt{ }$ \\
\hline Avalia os custos ambientais sob a ótica de atividades e processos & & $\sqrt{ }$ & $\sqrt{ }$ & $\sqrt{ }$ & & $\sqrt{ }$ \\
\hline $\begin{array}{l}\text { Considera as perdas e as ineficiências do processo produtivo na } \\
\text { avaliação de custos ambientais }\end{array}$ & & & & $\sqrt{ }$ & & \\
\hline Insere os custos ambientais nos sistemas de avaliação da empresa & & & $\sqrt{ }$ & $\sqrt{ }$ & & $\sqrt{ }$ \\
\hline Considera aspectos e impactos ambientais na análise & & & & $\sqrt{ }$ & & $\sqrt{ }$ \\
\hline $\begin{array}{l}\text { Associa os custos ambientais com categorias de impacto } \\
\text { ambiental }\end{array}$ & & & $\sqrt{ }$ & $\sqrt{ }$ & & \\
\hline $\begin{array}{l}\text { Identifica e quantifica as etapas do processo que contribuem } \\
\text { preponderantemente para os custos ambientais }\end{array}$ & & & & & & $\sqrt{ }$ \\
\hline Possibilita o desdobramento da análise em partes do processo & & $\sqrt{ }$ & $\sqrt{ }$ & & & \\
\hline Avalia os lucros ambientais & & & $\sqrt{ }$ & $\sqrt{ }$ & & $\sqrt{ }$ \\
\hline $\begin{array}{l}\text { Propõe ações de melhorias e avalia suas relações com a redução } \\
\text { dos custos ambientais }\end{array}$ & & $\sqrt{ }$ & $\sqrt{ }$ & & & $\sqrt{ }$ \\
\hline Compara os custos ambientais e os custos do produto & & & & & $\sqrt{ }$ & \\
\hline Metodologia de custeio empregada na avaliação & & & & $\begin{array}{l}\mathrm{ABC} / \\
\mathrm{FCA}\end{array}$ & & $\begin{array}{l}\mathrm{AB} \\
\mathrm{C}\end{array}$ \\
\hline
\end{tabular}

Figura 5 - Comparação entre os modelos apresentados 
A análise do quadro 3 revela que os modelos propostos por Regatschnig e Schnitzer (1998), Kraemer (2002) e Jasch (2003) são os que satisfazem a maioria dos critérios para a obtenção de um modelo de avaliação de custos ambientais completo e abrangente. Além disso, tanto o modelo de Kraemer, como o modelo de Jasch, utilizam-se do ABC para avaliar os custos ambientais, denotando que essa metodologia de custeio responde adequadamente as necessidades para realizar tal mensuração. A aplicação dessa metodologia para avaliação de custos ambientais, já foi identificado anteriormente por Verschoor e Reijnders (2001), em empresas multinacionais no contexto europeu.

Uma visão mais detalhada dos resultados do quadro 3 mostra que o modelo de Kraemer não associa os custos ambientais com as categorias de impacto ambiental, o que é realizado nos outros dois modelos citados. Já o modelo de Jasch não analisa como as ações de melhoria podem reduzir os custos ambientais, enquanto os modelos de Kraemer e Regatschnig e Schnitzer consideram esse aspecto. Por fim, enquanto o modelo de Jasch destaca-se pela inclusão das perdas e ineficiências do processo produtivo entre os custos ambientais, o modelo proposto por Kraemer é o único que identifica e quantifica as etapas do processo que contribuem preponderantemente para os custos ambientais. Desta forma, pode-se concluir que esses modelos se complementam e que uma abordagem capaz de congregar seus pontos positivos, suprindo deficiências particulares, tornaria a análise de custos ambientais mais efetiva e completa.

\section{Modelo proposto para a Avaliação de Custos Ambientais}

Com base nas definições de custos ambientais apresentadas por Jasch (2003) e Regastchnig e Schnitzer (1998), adota-se o seguinte conceito nesse trabalho: são os custos das atividades produtivas relacionados à geração de materiais ou a ações que causem ou possam causar danos ao meio ambiente, assim como atividades relacionadas ao seu tratamento, sua disposição ou sua prevenção.

Partindo-se dessa definição, da comparação entre os modelos realizada anteriormente e tomando-se como base os modelos propostos por Jasch (2003) e Kraemer (2002), elaborou-se uma nova abordagem para avaliar os custos ambientais em empresas industriais. Ela é composta de 10 etapas, as quais são descritas a seguir:

$1^{\text {a }}$. Etapa: Análise preliminar da empresa - visa a obtenção de um panorama da empresa em que será empregado o modelo. Para isso, deve-se identificar os produtos, os rejeitos, as principais matériasprimas utilizadas no processo produtivo, o consumo de energia e as atividades de prevenção de impactos ambientais desenvolvidas na organização. Além disso, também verifica-se a existência do Sistema de Gestão Ambiental, o sistema de custeio utilizado pela empresa e se ela possui certificações ambientais.

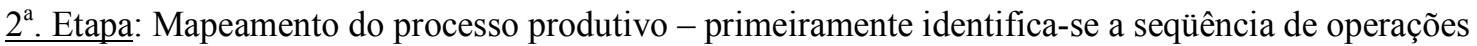
que compõem o processo produtivo para, após, listar e quantificar as entradas e as saídas de materiais de cada etapa, bem como o consumo de energia e a geração de rejeitos. A identificação dos equipamentos utilizados no processamento de materiais em cada operação e a mão-de-obra (horashomem) absorvida por elas complementam essa parte do modelo.

3. Etapa: Avaliação dos custos de cada operação - após a identificação das etapas que compõem o processo produtivo, deve-se analisar o quanto de recursos financeiros são consumidos por elas. Para isso, consideram-se os custos de materiais consumidos, de mão-de-obra, de energia e os custos indiretos (aluguel, atividades administrativas). Assim, pode-se escrever a equação (1).

$$
C O(j)=M P(j)+M O D(j)+E(j)+C I(j)
$$

em que: $C O(j)$ é o custo da operação $j$ analisada

$M P(j)$ é o custo dos materiais consumidos na operação $j$;

$M O D(j)$ é o custo da mão-de-obra direta relacionada com a operação $j$;

$E(j)$ é o custo devido ao consumo de energia na operação $j$; 
$C I(j)$ corresponde aos custos indiretos da operação $j$.

Por questão de nomenclatura, define-se

$$
C P(j)=M O D(j)+E(j)+C I(j)
$$

em que: $C P(j)$ são os custos de produção associados a operação $j$.

4 . Etapa: Análise dos rejeitos - envolve a identificação da operação em que cada rejeito é gerado e sua classificação quanto: ao estado físico (emissão, efluente ou resíduo); ao seu destino (atmosfera, esgoto, tratamento de efluentes, aterro); ao meio diretamente impactado pela sua geração ou que poderia ser caso não houvesse tratamento (ar, solo, água) e, ainda, à sua origem (matéria-prima não consumida, auxiliares de processo, produto intermediário perdido, limpeza de equipamentos). Esta classificação será importante para as avaliações realizadas a posteriori.

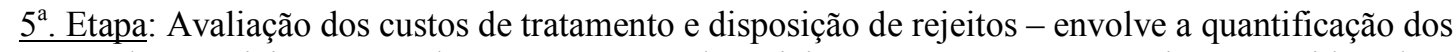
custos de materiais empregados no tratamento dos rejeitos, os gastos com energia consumida pelos equipamentos utilizados nesse tratamento, os gastos com mão-de-obra envolvida nessa atividade e os custos indiretos associados (aluguel e custos administrativos).

6 ${ }^{\mathrm{a}}$. Etapa: Avaliação dos custos de geração de rejeitos - nesta etapa avalia-se a parcela dos custos de produção que estão relacionadas à geração dos rejeitos, considerando-se também a parcela dos custos das matérias-primas, dos auxiliares ou dos produtos intermediários que lhe deram origem e que foram identificados na $4^{\text {a }}$. etapa do modelo. Logo,

$$
C G(j)=\sum_{i=1}^{n}\left(C M_{i j}\right)+w_{j} \cdot C P_{j}
$$

em que: $C G(j)$ é o custo de geração de rejeitos devido à operação $j$ do processo produtivo;

$C M_{i j}$ é a parcela dos custos do material $i$ perdido na operação $j$ do processo produtivo;

$w_{j}$ é o fator que associa os custos operacionais da operação $j$ com a geração de rejeitos.

$7^{\mathrm{a}}$. Etapa: Avaliação dos custos de tratamento de rejeitos associados com cada operação do processo produtivo - envolve a distribuição dos custos totais de tratamento e disposição de rejeitos quantificados na $5^{\text {a }}$. etapa do modelo entre as operações do processo produtivo. Para isso, deve-se considerar as relações de causa-efeito entre o rejeito e o tratamento, assim como direcionadores que permitam relacionar a quantidade do rejeito gerado com o custo de tratamento.

$$
C T D(j)=\sum_{i=1}^{n} x_{i j} C L+\sum_{i=1}^{n} y_{i j} C R+\sum_{i=1}^{n} z_{i j} C E
$$

em que: $C T D(j)$ é o custo de tratamento e disposição da operação $j$ do processo produtivo;

$C L$ é o custo total com o tratamento de efluentes líquidos;

$C R$ é o custo total com o tratamento e disposição de resíduos sólidos;

$C E$ é o custo total com o tratamento de emissões gasosas;

$x_{i j}$ é o direcionador de custo de tratamento de efluentes devido ao rejeito $i$ na operação $j$; operação $j$;

$y_{i j}$ é o direcionador de custo de tratamento e disposição de resíduos devido ao rejeito $i$ na

$z_{i j}$ é o direcionador de custo de tratamento de emissões devido ao rejeito $i$ na operação $j$.

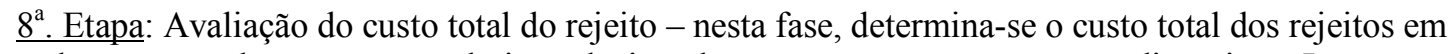
cada operação do processo produtivo relacionado a sua geração, tratamento e disposição. Logo:

$$
\text { CTR }(j)=C G(j)+C T D \quad(j)
$$


em que:CTR (j) é o custo total do rejeito da operação $j$ do processo produtivo.

9 . Etapa: Avaliação das atividades de prevenção de impactos ambientais - envolve a análise e quantificação dos custos das atividades que são desenvolvidas na empresa, cuja finalidade é evitar a ocorrência de impactos ambientais e geração de rejeitos. Alguns exemplos de atividades de prevenção são tratamento de águas, preparo e condicionamento de matérias-primas e auxiliares de processo, treinamento de operadores, auditorias ambientais e gastos com o Sistema de Gestão Ambiental, se for o caso.

Por fim, pode-se determinar o custo ambiental do processo produtivo analisado, de acordo com a definição anterior, utilizando-se a equação (6).

$$
C A=\sum_{j=1}^{m} C T R(j)+C P V
$$

em que:CA é o custo ambiental total do processo produtivo;

CPV é o custo total das atividades de prevenção.

$10^{\mathrm{a}}$. Etapa: Interpretação dos resultados - nesta fase final, os resultados são analisados para poder tecer algumas conclusões sobre o desempenho atual da empresa estudada. Tais análises envolvem a comparação entre:

a) os custos de prevenção ( $9^{\mathrm{a}}$. etapa) e de correção ( $5^{\mathrm{a}}$. etapa);

b) os custos de geração ( $6^{\mathrm{a}}$. etapa) e de tratamento e disposição ( $7^{\mathrm{a}}$. etapa);

c) os custos ambientais e os custos de produção.

Com isso, pode-se verificar se a empresa tem uma atitude proativa ou reativa à preservação ambiental, o quanto os custos ambientais representam nos custos de produção e qual etapa do processo produtivo apresenta maiores gastos ambientais, para priorizá-las e realizar uma análise mais detalhada, visando propor ações de melhoria.

\section{Contra-ponto à necessidade de Avaliação de Custos Ambientais}

O monitoramento é uma atividade crítica para o gerenciamento ambiental e deve ser realizado fisica e economicamente. O primeiro consiste em balanços de massa e de energia entre as correntes de entrada e de saída do processo. Já o segundo está focado na integração de todos os custos ambientais aos custos do produto (VERSCHOOR e REIJNDERS, 2001). Porém, seriam essas informações suficientes para criar uma posição proativa por parte dos empresários? Para responder a esta questão Eagan e Joeres (2001) realizaram entrevistas com diretores e gerentes de empresas, dos quais cinco estavam diretamente ligados aos processos produtivos.

Conforme os pesquisadores, muitos profissionais vêem os custos ambientais como a principal ligação entre impactos ambientais e os processos de manufatura. Essa hipótese é sustentada na crença de que melhores informações sobre impacto ambiental implicam um melhor desempenho para a empresa. Conforme constatado no estudo, somente as informações de custos não induzem significantes mudanças ambientais em manufaturas. Essa conclusão parece contraditória com as atitudes gerenciais nas quais o conhecimento dos custos é fundamental no processo de tomada de decisão. No entanto, os autores observaram que a complexidade da estrutura organizacional é um empecílio à implantação de mudanças. Além disso, o fato da dificuldade no reconhecimento das implicações ambientais associadas às atividades da empresa dificulta o desdobramento de ações preventivas.

Eagan e Joeres (2001) salientam que as conclusões obtidas a partir desse estudo não podem ser generalizadas. Eles citam, ainda, que as informações de custos ambientais resultam em uma atitude mais ativa em empresas cujos produtos tenham impactos ambientais mais significativos ou nas quais esses custos representem uma grande parcela do custo do produto final. 


\section{Conclusões}

Atualmente, o gerenciamento ambiental é utilizado por um número significativo de empresas. Em contrapartida, observa-se uma deficiência ao mensurar os custos ambientais. Alguns autores, conforme citado neste trabalho, argumentam que há uma relação direta entre os impactos ambientais e os custos associados. No entanto, admitem a inexistência de uma metodologia consolidada capaz de relacionar esses dois assuntos.

Em geral, a literatura apresenta como causa dessa deficiência a falta de definições sobre custos ambientais e a dificuldade em mensurá-los, pois são formados por uma grande parcela de custos intangíveis. Diante dessa situação, costuma-se colocar os custos ambientais como externalidades.

Para solucionar este problema, alguns modelos foram propostos na tentativa de estudar as origens desses custos, de forma que possam ser melhor analisados e, então, reduzidos. Mesmo assim, a comparação entre os modelos revela que cada um possui um enfoque distinto, implicando a necessidade de uma abordagem capaz de congregar os pontos positivos de cada proposta. Assim, nesse trabalho apresentou-se um modelo visando alcançar tal objetivo. No entanto, salienta-se a necessidade de empregá-lo em alguns segmentos industriais para verificar seu desempenho e identificar possíveis limitações.

\section{Referências}

AMMENBERG, J.; HJELM, O. The connection between environmental management systems and continual environmental performance improvements. International Journal of Corporate Sustainability, v. 9, p. 183-192, 2002.

AZAPAGIC A., CLIFT R. Life cycle assessment and multiobjective optimization. Journal of Cleaner Production, v. 7, p. 135-143, 1999.

BAKSHI, B.R. A thermodynamic framework for ecologically conscious process systems engineering. Computers and Chemical Engineering, v. 24, p. 1767-1773, 2000.

BENAKOUCHE, R.; CRUZ, R. S. Avaliação Monetária do Meio Ambiente, São Paulo: Makron Books, 1994.

BURGESS, A.A.; BRENNAN, D.J. Application of life cycle assessment to chemical processes. Chemical Engineering Science, v. 56, p. 2589-2604, 2001.

CAMPOS, L.M.S. Um estudo para definição e identificação dos custos da qualidade ambiental, Florianópolis, 1996, Dissertação de Mestrado - Curso de Pós-Graduação em Engenharia de Produção. Universidade Federal de Santa Catarina.

CHANDRASHEKAR A., DOUGLESS T., AVERY G. C. The environmental is free: the quality analogy. Journal of Quality Management, v. 4, n. 1, p. 123-143, 1999.

DIEPENDAAL, M.J.; WALLE, F.B. A model for environmental costs for corporations (MEC). Waste Management \& Research, v. 12, p. 429-439, 1994.

DONAIRE, D. Gestão Ambiental na Empresa, São Paulo: Editora Atlas, 1999.

DURAIRAJ, S.K.; ONG, S.K.; NEE, A.Y.C.; TAN, R.B.H. Evaluation of life cycle cost analysis methodologies. Corporate Environmental Strategy, v. 9, p. 30-39, 2002.

EAGAN, P.D.; JOERES, E. The utility of environmental impact information: a manufacturing case study. Journal of Cleaner Production, v. 10, p. 75-83, 2002. 
HANSEN D. R., MOWEN M. M. Gestão de Custos - Contabilidade e Controle, Tradução da 3a. edição norte-americana, São Paulo: Pioneira Thomson Learning, 2001.

JASCH C. The use of Environmental Management Accounting (EMA) for identifying environmental costs. Journal of Cleaner Production, v. 11, p. 667-676, 2003.

KRAEMER T. H. Modelo Econômico de Gestão Ambiental. Florianópolis, 2002, Qualificação de Doutorado - Curso de Pós-Graduação em Engenharia de Produção. Universidade Federal de Santa Catarina, Santa Catariana.

MEINDERS, H.; MEUFFELS, M. Product Chain Responsibility - An industry perspective. Corporate Environmental Strategy, v. 8, p. 348-354, 2001.

REGATSCHNIG, H.D.; SCHNITZER, H. A techno-economic approach to link waste minimization technologies with the reduction of corporate environmental costs: effects on the resource and energy efficiency of production. Journal of Cleaner Production, v. 6, p. 213-225, 1998.

VERSCHOOR, A.H.; REIJNDERS, L. The environmental monitoring of large international companies. How and what is monitored and why. Journal of Cleaner Production, v. 9, p. 43-55, 2001. 